\title{
Primary energy sources planning based on demand forecasting: The case of Turkey
}

\author{
Coşkun Hamzaçebi* \\ Karadeniz Technical University, Department of Industrial Engineering, Trabzon, Turkey
}

\begin{abstract}
Forecasting electricity consumption is a very important issue for governments and electricity related foundations of public sector. Recently, Grey Modelling (GM (1,1)) has been used to forecast electricity demand successfully. GM $(1,1)$ is useful when the observed data is limited, and it does not require any preliminary information about the data distribution. However, the original form of GM $(1,1)$ needs some improvements in order to use for time series, which exhibit seasonality. In this study, a grey forecasting model which is called SGM $(1,1)$ is proposed to give the forecasting ability to the basic form of $G M(1,1)$ in order to overcome seasonality issues. The proposed model is then used to forecast the monthly electricity demand of Turkey between 2015 and 2020. Obtained forecasting values were used to plan the primary energy sources of electricity production. The findings of the study may guide the planning of future plant investments and maintenance operations in Turkey. Moreover, the method can also be applied to predict seasonal electricity demand of any other country.
\end{abstract}

Keywords: electricity demand, forecasting, seasonal grey modelling, resource planning

\section{Introduction}

Turkey has a strategic location between Asia and Europe due to its role in energy sources distribution. Turkey has shown a significant growth in population, GDP and energy consumption in the last two decades. The population and the GDP of Turkey reached approximately 76 million people and $\$ 822$ billion in 2013 with an average increase of $2.1 \%$ and $17 \%$ compared with 1993, respectively (TSI, 2013).

* Tel: +904623772950

E-mail: hamzacebi@ktu.edu.tr

DOI: http://dx.doi.org/10.17159/2413-3051/2016/v27i1a1560
The electricity consumption of Turkey reached 198041.6 million $\mathrm{kWh}$ in 2013 with an increase of 234.3\% compared to 1993 (MENR, 2013; EGC, 2013). According to the International Energy Agency (IEA), Turkey's energy demand will expand faster than other member countries of IEA over the medium to long-term. The mentioned report states that the energy usage of Turkey will be roughly doubled compared with the current consumption over the next decade and also its electrical energy demand will grow more rapidly (IEA, 2009).

Forecasting of electricity consumption is a very vital issue for governments and electricity related foundations of public sector because of planning the future investments. Therefore, prediction of energy consumption with a high degree of accuracy has two important issues for decision makers. The first is to meet the future demand and the other issue is to execute the reliable energy policies for sustainable development (Hamzacebi and Es, 2014).

In the literature, the used techniques for prediction of electricity consumption are mainly based on statistics and machine learning. Although several different forecasting methods are used for prediction of electricity demand, none of them is superior in all cases. Some of these techniques used to forecast electricity demand of countries are the time series model (Saab et al., 2001; Sa'ad, 2009; Dilaver and Hunt, 2011; Boran, 2014; Efendi et al., 2014), artificial neural networks (ANNs) model (Hamzacebi and Kutay, 2004; Hamzacebi, 2007; Azadeh et al., 2008; Cunkas and Altun, 2010; Panklib et al., 2015), regression and econometric model (Mohamed and Bodger, 2005; Al-Shobaki and Mohsen, 2008; Meng and Niu, 2011; Bildirici et al., 2012; Bianco et al., 2013), neuro-fuzyy model (Demirel et al., 2010; Chang et al., 2011), heuristic optimization method (El-Telbany and ElKarmi, 2008; Cunkas and Taskiran, 2011; Zhu et al., 2011), and support vector regression model 
(SVR) (De Felice et al., 2015; Jain et al., 2014; Kaytez et al., 2015).

Almost all of the studies mentioned above are on an annual prediction basis. The annual predictions may be useful for investments planning, but the seasonal effects need to be taken into account for the maximum capacity planning. The modelling of seasonal patterns is important for both electrical energy demand forecasting and sustainable electricity supply (Herrerias, 2013). There are several studies based on statistical or machine learning prediction in the literature, which deal with seasonality. González-Romera et al. (2008) investigated the periodic behavior of the Spanish monthly electricity demand series, and the authors proposed a novel hybrid approach based on a Fourier series while the trend is predicted with a neural network. Wang et al. (2009) proposed a combined e-SVR model considering seasonal proportions based on development tendencies from historical data, which forecasted the northeast electricity demand of China. Sumer et al. (2009) used ARIMA, seasonal ARIMA (SARIMA) and alternatively the regression model with seasonal latent variable in forecasting electricity consumption. The authors examined the advantage of forecasting with the SARIMA method. Zhu et al. (2011) developed an improved hybrid model for electricity demand in China, which takes the advantages of moving average procedure, combined method, hybrid model and adaptive particle swarm optimization algorithm, known as MA-C-WH. Wang et al. (2012) applied particle swarm optimization (PSO) optimal Fourier method, seasonal ARIMA model and combined models of PSO optimal Fourier method with seasonal ARIMA. Ju and Hong (2013) proposed a SVR based forecasting model to deal with seasonal electricity tendency. De Felice (2015) introduced an application of climate information for the energy sector at seasonal time-scales. The authors analyzed the effectiveness of seasonal climate forecasts for electricity demand forecasting both considering deterministic and probabilistic approaches. The subject of prediction of the seasonal electricity consumption has a growing interest and there are still open issues to be studied.

A novel forecasting method called the grey prediction model was introduced by Deng in 1980s (Deng, 1982). The most widely used of these models is the GM $(1,1)$. The GM $(1,1)$ can be used when the size of input data is small for times series forecasting (Liu and Lin, 2010). The GM $(1,1)$ has been used as a prediction tool in several different areas (Sum, 1991; Zhu and Cao, 1998; Wang, 2002; Mao and Chirwa, 2006; Chiang and Chen et al., 2008); Tang and Yin, 2012). Energy demand forecasting is another important usage area of grey prediction models (Yao et al., 2003; Zhou et al., 2006; Akay and Atak, 2007; Hsu and Chen, 2012; Chena and Wang, 2012; Lü and Lu, 2012; Chang et al., 2013).
Although GM $(1,1)$ is a powerful time series forecasting technique, the basic form of GM $(1,1)$ cannot give satisfactory performance in seasonal time series forecasting. In this paper, motivated by a desire to improve the performance of GM $(1,1)$ in seasonal time series forecasting, a new grey forecasting model called SGM $(1,1)$ is proposed. The proposed model gives the forecasting ability to the basic form of GM $(1,1)$ in order to overcome seasonality issues. This is the main contribution of this paper to the literature. While there are other techniques that deal with seasonality, the $\operatorname{SGM}(1,1)$ is simple and stable. Besides, it does not depend on cases where assumptions are deduced and it can be applied also when the data is limited.

The proposed model was used in this study to make monthly electrical energy demand forecasts for Turkey for the period 2015-2020. The main objective of this study is to show another way to forecast seasonal electricity demand easily and to make resource planning on thebases of these forecast values. The remainder of the study is organized as follows. In section 2 , the basic GM $(1,1)$ and the SGM $(1,1)$ were introduced, and a brief knowledge about the resource planning of Turkey's electricity demand were given. Section 3 deals with the obtained results and Section 4 discusses them. Finally, the conclusions are given.

\section{Methods}

The grey systems theory (GST) deals with uncertainty. The GST was established by Julong Deng in the beginning of 1980s (Deng, 1982). The GST shows its superiority when the problem has less data and partially known information. The GST has been used in real world problems such as management science, economic, engineering and social sciences (Liu and Lin, 2010). The GST includes GM $(1,1)$, GM $(2,1)$, GM $(0, N)$, GM $(1, N)$ and Grey Verhulst Models as prediction approaches. Nevertheless, GM $(1,1)$ is the most preferred model for times series forecasting.

\subsection{Basic GM $(1,1)$}

GM $(1,1)$ is the most widely used prediction model based on time series forecasting when the observed data is limited. The notations $(1,1)$ present the first order single variable prediction. The GM $(1,1)$ is a non-rigid model because of the independence to any initial knowledge about probability distribution of the data (Liu and Lin, 2010; Hamzacebi and Es, 2014).

The GM $(1,1)$ includes three basic phases (Liu and Lin, 2010; Hamzacebi and Es, 2014):

(i) Accumulated generation operation (AGO)

(ii) Grey modelling

(iii) Inverse accumulated generation operation (IAGO)

The algorithm of GM $(1,1)$ is as follows: 
Step 1: For the initial time sequence

$$
\begin{aligned}
& X^{0}=\left\{X_{1}^{0}, X_{2}^{0}, X_{3}^{0}, \ldots \ldots, X_{n}^{0}\right\} \\
& =\left(X_{1}^{0} ; \quad t=1,2,3, \ldots, n ; n \geq 4\right)
\end{aligned}
$$

where $X_{1}^{0}$ should be a non-negative sequence.

Step 2: Accumulated generation operation (AGO) When the AGO is implemented to above sequence, the below sequence $X^{1}$ can be obtained. The $X^{1} X^{1}$ sequence is a monotonically increasing series.

$$
\begin{aligned}
& X^{1}=\left\{X_{1}^{1}, X_{2}^{1}, X_{3}^{1}, \ldots \ldots, X_{n}^{1}\right\} \\
& =\left(X_{t}^{1} ; \quad t=1,2,3, \ldots, n ; n \geq 4\right)
\end{aligned}
$$

where

$$
X_{k}^{1}=\left\{\sum_{t=1}^{k} X_{t}^{0}, t=1,2, \ldots, n ; k=1,2, \ldots, n\right\}
$$

Step 3: Grey modelling

By applying a first order grey differential equation, grey modelling can be obtained.

$$
X_{t}^{o}+a Z_{t}^{1}=b, \quad t=2, \ldots, n
$$

where

$$
Z_{t}^{1}=\theta X_{t}^{1}+(1-\theta) X_{t-1}^{1}, \quad t=2, . ., n(5)
$$

$\theta$ denotes an adjustment coefficient, and $0<\theta<1$. The $\theta$ value is important in order to decrease the forecasting error. In Equation (4), ' $a$ ' is called the development coefficient and ' $b$ ' is called driving coefficient. Applying least square method coefficients, $[\mathrm{a}, \mathrm{b}]^{\mathrm{T}}$ can be estimated as

$$
A=\left[\begin{array}{l}
a \\
b
\end{array}\right]=\left(B^{T} B\right)^{-1} B^{T} Y
$$

where

$$
\begin{aligned}
& B=\left[\begin{array}{cc}
-Z_{2}^{1} & 1 \\
-Z_{3}^{1} & 1 \\
\ldots . & \ldots \\
-Z_{n}^{1} & 1
\end{array}\right], Y=\left[\begin{array}{c}
X_{2}^{0} \\
X_{3}^{0} \\
\ldots . . \\
X_{n}^{0}
\end{array}\right] \\
& Y=B A
\end{aligned}
$$

Step 4: Whitenization processes

The whitenization processes occur as below:

$$
\frac{d X_{t}^{1}}{d t}+a X_{t}^{1}=b
$$

By using $a$ and $b$ coefficients the prediction model of $X^{1}$ sequence can be obtained.

$$
X_{t+1}^{\prime}=\left[X_{1}^{0}-\frac{b}{a}\right] e^{-a t}+\frac{b}{a}, \quad t=0,1,2, \ldots
$$

Step 5: Inverse accumulated generation operation (IAGO)

By implementing IAGO the prediction values of original sequence can be obtained:

$$
X_{1+1}^{0}=X_{1+1}^{1}-X_{1}^{1}
$$

If Eq. (9) is substituted in Eq. (10) then Eq. (11) is obtained as

$$
\hat{\mathrm{X}}_{\mathrm{t}+1}^{0}=\left(1-\mathrm{e}^{\mathrm{a}}\right)\left[\mathrm{X}_{1}^{0}-\frac{\mathrm{b}}{\mathrm{a}}\right] \mathrm{e}^{-\mathrm{at}}
$$

\subsection{Grey Seasonal Forecasting Method}

Many time series exhibit cyclic variation known as seasonality. Seasonal changes are part of a time series around one year. The seasonality can be detected by measuring the value of related variable for small time intervals, such as days, weeks, months or quarters. Seasonality occurs in many time series related to real world problems especially in economy, business and energy. In the literature, seasonality has been modeled by using different approaches. One of the best-known approaches is the seasonal ARIMA model. However, this technique needs at least 50 data for modelling (Box et al., 2008).

Grey modelling theory can be used for seasonality but the basic form of GM $(1,1)$ cannot give satisfactory performance when predicting the times series with seasonality (Tseng et al. 2001). In the literature, the only work on seasonal times series forecasting by GM $(1,1)$ was conducted by Tseng et al. (2001). However, Tseng et al. (2001) proposed to remove the seasonal effect from the data. Despite this approach being acceptable, it is not practical because of the data loss.

The proposed SGM $(1,1)$ model in this study can be used for seasonal time series forecasting. The model needs at least 4 seasonal data. The prediction value of the any seasonal period can be forecasted using only the past observation values of $\mathrm{k} \geq 4$ seasonal terms. The training mechanism of SGM $(1,1)$ according to the size of forecasting horizon (h) is stated as follows: 
$\hat{X}_{t+1}=\operatorname{GM}(1,1)\left[X_{t-s+1}, X_{t-2 s+1}, \ldots, X_{t-k s+1}\right]$

$\hat{X}_{t+2}=\operatorname{GM}(1,1)\left[X_{t-s+2}, X_{t-2 s+2}, \ldots, X_{t-k s+2}\right](13)$

$\hat{X}_{t+h}=\operatorname{GM}(1,1)\left[X_{t-s+h}, X_{t-2 s+h}, \ldots, X_{t-k s+h}\right](14)$

where s denotes the seasonality degree.

It can be deduced from above equations (12-14) that $\operatorname{SGM}(1,1)$ selects the required sequence from the whole series and then runs the GM $(1,1)$ for selected sequences. The selection of the required sequence is the novelty of the model. This procedure may be simple but it provides a considerable improvement.

The simplicity of the SGM $(1,1)$ is the main advantage of the model. The SGM $(1,1)$ does not need any priori information or assumption of the series or any preliminary calculation for model detection while SARIMA models need to investigation of best structure by using autocorrelations. In modelling phase of SGM $(1,1)$, only $\theta$ parameter can take different values $(0<\theta<1)$ but this procedure can be simplified by programming.

\subsection{Resource planning of Turkey's electricity demand}

While performing the monthly resource planning of Turkey's electricity demand until 2020, a systematic process was implemented successively as seen in Figure 1. The data was collected, and then split into two parts as modelling and test sets, the GM $(1,1)$ and SGM $(1,1)$ models were built with modelling data, and in this step three values of $\theta$ parameter (low: $\theta=0.1$, medium: $\theta=0.5$, high: $\theta=0.9$ ) was considered. The models were test with test set data. Hence, the best value of $\theta$ parameter was determined and the prediction performances of the models were compared. After the selection of the best model, the future electricity demand of Turkey was forecasted. Finally, amount of each source such as natural gas, hydraulic, thermal, renewable etc. in the electrical energy production was determined to meet the forecasted electricity demand.

\subsubsection{Data}

The data were taken from TSI (2013), which is complete, robust and reliable. The data present the value of monthly electricity consumption from 1987 to 2014. In order to make parameter optimization of SGM $(1,1)$ model, the data were divided into two parts referred to as the modelling data and the test data. While the observations of the monthly electricity consumption during the years 1987 to the year before 2014 belonged to the modelling data, and the rest belonged to the test data.

\subsubsection{Performance measures}

Different performance measures can be used to determine the accuracy of the prediction models. In this study, four performance measures were used. These measures are

$$
\text { Mean Absolute Error (MAE) }=\frac{1}{n} \sum_{i=1}^{n}\left|\mathcal{e}_{i}\right|
$$

$$
\begin{aligned}
& \text { Mean Absolute Percentage Error (MAPE) }= \\
& \frac{1}{n} \sum_{i=1}^{n}\left|\frac{e_{i}}{Y_{i}}\right| * 100
\end{aligned}
$$

Root Mean Square Error (RMSE) $=$

$$
\begin{aligned}
& \sqrt{\frac{1}{n} \sum_{i=1}^{n} e_{i}^{2}} \\
& \text { Post Error Ratio }(\mathrm{C})=\frac{\mathrm{s}_{2}}{\mathrm{~s}_{1}}
\end{aligned}
$$

where, $\mathrm{n}$ represents the size of the data, $e_{\mathrm{i}}$ and $\mathrm{Y}_{\mathrm{i}}$ denote the error value and the observation value of

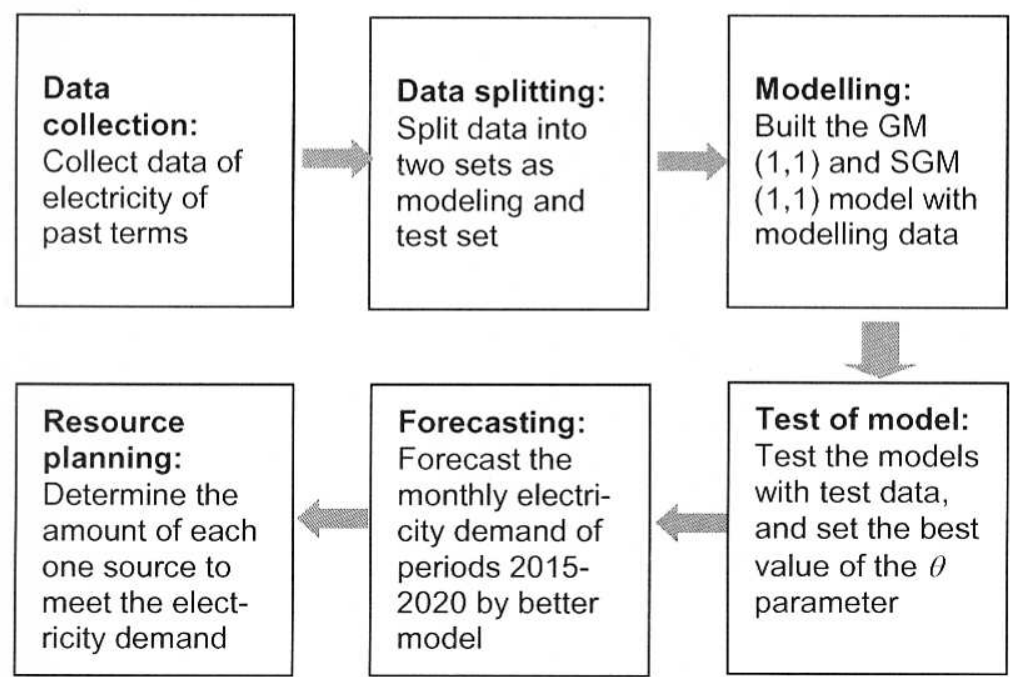

Figure 1: The flowchart of resource planning of Turkey's electricity demand 
the ith period, $S_{1}$ and $S_{2}$ represent the standard deviations of original data and of the errors, respectively. Lower values of all performance measures indicate the superior prediction. As stated in literature, values smaller than $10 \%$ of MAPE present a successful prediction. Adequacy levels for MAPE and $\mathrm{C}$ are presented in Table 1 according to Liu and Lin (2010).

Table 1: Adequacy levels for MAPE and C

\begin{tabular}{lcc}
\hline Threshold & & \\
\hline Accuracy scale & MAPE & C \\
\hline 1st level (Perfect) & $\leq 1$ & $\leq 0.35$ \\
\hline 2nd level (Well) & $\leq 5$ & $\leq 0.50$ \\
\hline 3th level (Acceptable) & $\leq 10$ & $\leq 0.65$ \\
\hline 4th level (Incapable) & $>10$ & $>0.65$ \\
\hline
\end{tabular}

\section{Results}

In order to obtain the best performance with both models, several experiments were conducted. The selected model was then used for forecasting. The best value of was found as 0.5 for both methods. The results shownn in Table 2 were obtained for the test set after implementation of both GM $(1,1)$ and $\operatorname{SGM}(1,1)$.

Table 2: Performances of GM $(1,1)$ and SGM $(1,1)$ for test set

\begin{tabular}{|c|c|c|c|c|}
\hline & \multicolumn{2}{|c|}{ Modelling set } & \multicolumn{2}{|c|}{ Test set } \\
\hline & $G M(1,1)$ & $\operatorname{SGM}(1,1)$ & GM $(1,1$ & $S G M(1,1)$ \\
\hline MAPE & $7.18 \%$ & $4.23 \%$ & $8.39 \%$ & $5.18 \%$ \\
\hline MAE & 716.0 & 515.3 & 1627.9 & 1078.9 \\
\hline RMSE & 977.4 & 726.9 & 1911.4 & 1194.2 \\
\hline $\mathrm{C}$ & 0.1654 & 0.142 & 0.5441 & 0.4310 \\
\hline
\end{tabular}

Figure 2 shows the performance of GM $(1,1)$ and SGM $(1,1)$ compared with the actual values graphically for the test set.

It can be easily deduced from Table 2 that the SGM $(1,1)$ shows better performance than GM $(1,1)$. In addition to this, results in Table 2 indicate a good forecasting for the SGM $(1,1)$ using the adequacy levels presented in Table 1. As can be seen in Figure 2, GM $(1,1)$ could forecast the irregular and trend components of the series but could not forecast the seasonality. However, the SGM $(1,1)$ can forecast the irregular, trend and seasonal components of the series. This difference was due to selecting the appropriate data by suggested model.

By using the SGM $(1,1)$, monthly electricity demand of Turkey was forecasted until the year 2020. The forecasting values of electricity demand are given in Table 3. Figure 3 shows the past and future behavior of the electricity demand.

\section{Discussion}

As can be seen from Figure 3, the increment ratio of electricity demand is decreasing. The average increment ratio was equal to $12.53 \%$ for the period 1991-2000 compared with $7.34 \%$ for 2001-2010, while, according to the forecasting results, it became $6.05 \%$ for the 2014-2020 forecasting period. From this point it can be said that the SGM $(1,1)$ model has adopted the behaviour of demand series and implemented it for the forecasting issue. Besides, the post error ratio of SGM $(1,1)$ was found to be 0.142 and 0.431 for modelling and test sets, respectively. These results indicate perfect performance for modelling set and well performance for test set according to the scale given in Table 1. Post error ratio is an important performance measure because it shows that the variance of errors is relatively smaller than variance of original data.

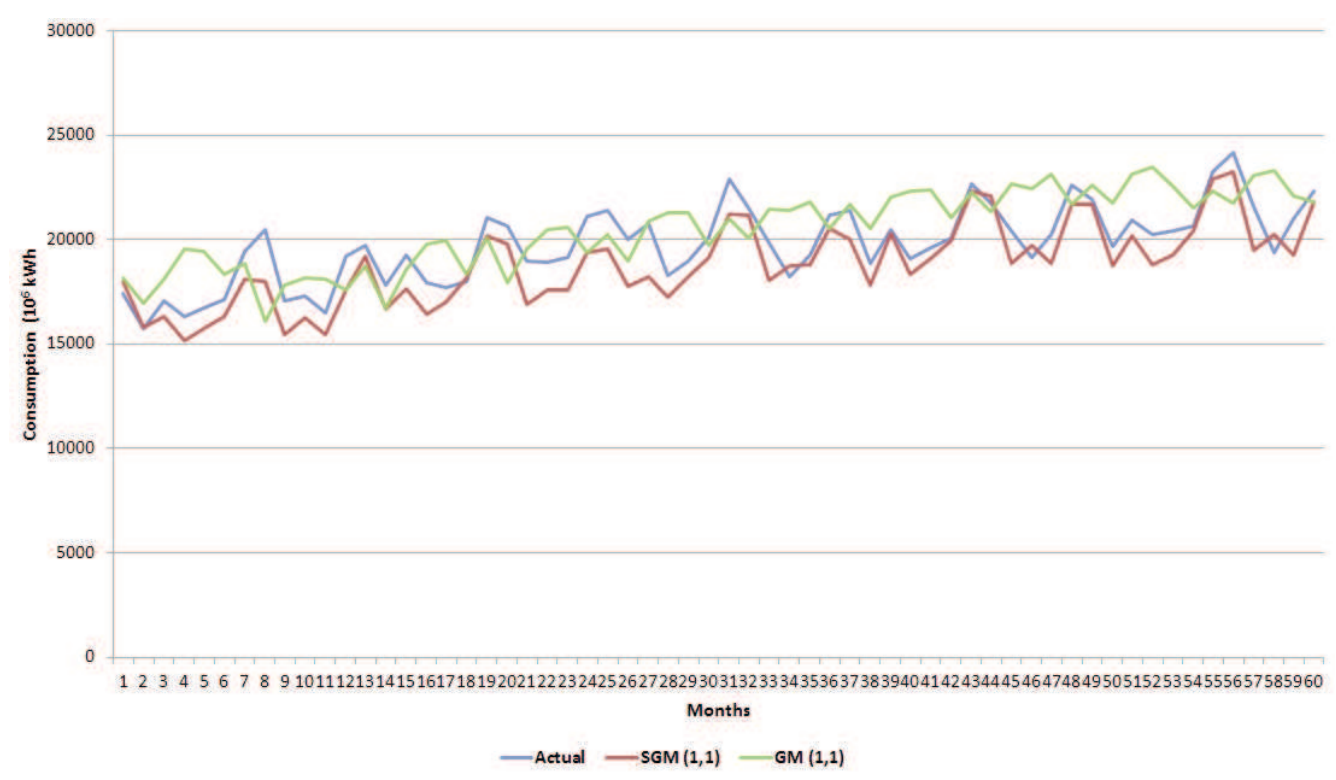

Figure 2: Comparison of both methods for the test set 


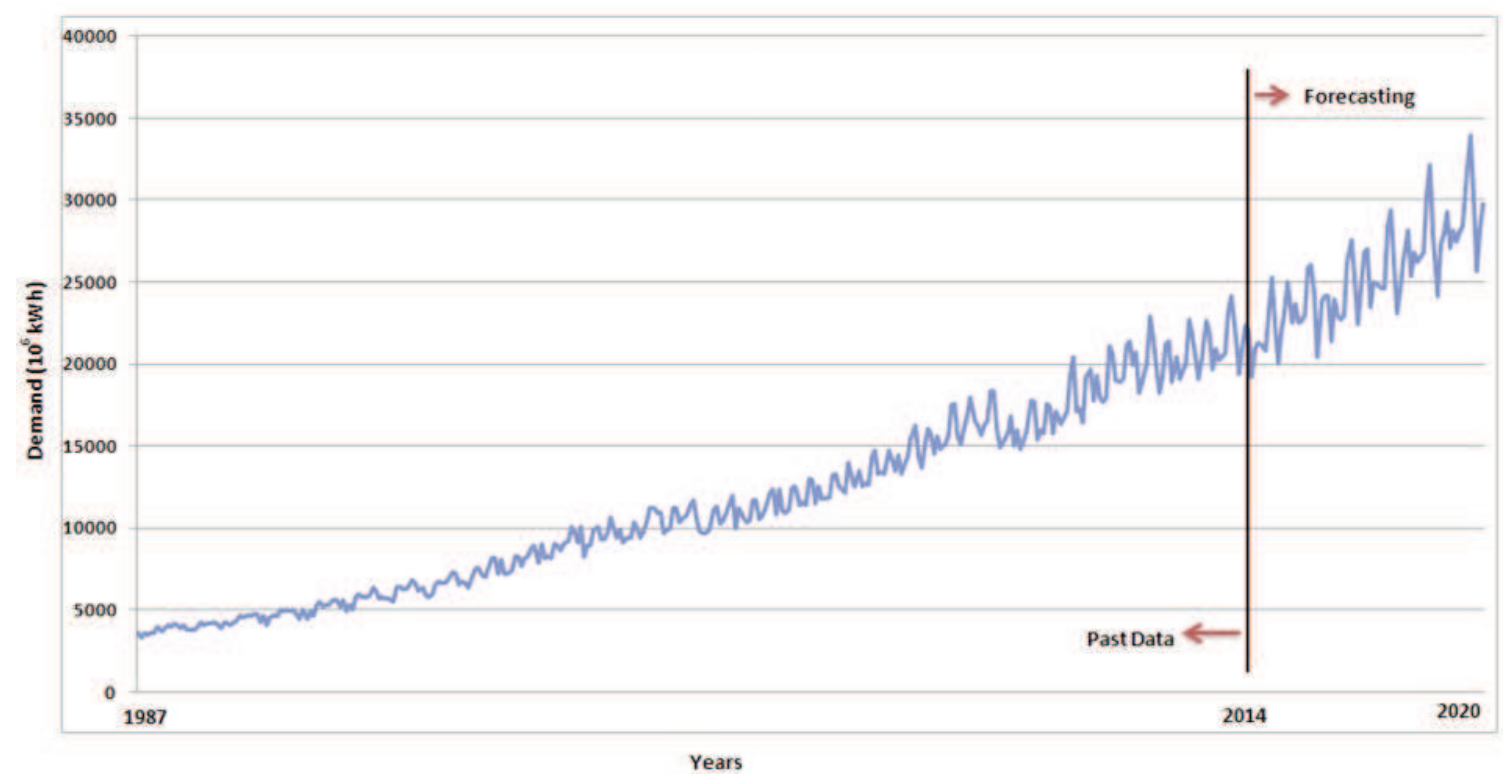

Figure 3: Monthly electricity demand until 2020

Table 3: Forecasting values

\begin{tabular}{llllllllllllll} 
Year & \multicolumn{1}{c}{ Monthly electricity demand forecasting of Turkey until 2020 ( $106 \mathrm{kWh})$} \\
\hline & Jan. & Feb. & Mar. & Apr. & May & June & July & Aug. & Sep. & Oct. & Nov. & Dec. \\
\hline 2015 & 22074 & 19190 & 20902 & 21312 & 21170 & 20834 & 23291 & 25317 & 22364 & 20085 & 22005 & 23198 \\
\hline 2016 & 24981 & 22558 & 23636 & 22576 & 22675 & 22973 & 25819 & 26096 & 24322 & 20459 & 23830 & 24159 \\
\hline 2017 & 24144 & 21402 & 23925 & 23040 & 22707 & 22928 & 26233 & 27583 & 24991 & 22484 & 24674 & 26857 \\
\hline 2018 & 27016 & 23507 & 25021 & 24865 & 24630 & 24652 & 28391 & 29427 & 26142 & 23111 & 24496 & 26295 \\
\hline 2019 & 28184 & 25425 & 26766 & 26224 & 26503 & 26847 & 30387 & 32112 & 27867 & 24177 & 27293 & 27999 \\
\hline 2020 & 29272 & 27141 & 28172 & 27526 & 28084 & 28459 & 32033 & 33970 & 30123 & 25639 & 28277 & 29793 \\
\hline
\end{tabular}

The results in Table 3 can also be used to deduce the maximum requirements of the sources that emerged in August for every year. Determination of maximum requirements of the sources is essential for planning future plant investment as well as making arrangement of maintenance operations and sustainable electricity supply. These findings may also guide the import and export policies.

Another substantive point of discussion is the absence of any comparison with the other seasonal forecasting methods such as SARIMA and ANNs. The absence is caused by the following:

(i) It is clear in literature that none of the forecasting techniques give superior performance for all-time series. The thrust of this paper is to improve the prediction ability of the GM $(1,1)$ in seasonal time series forecasting because of its simplicity and stability for all applications. Once the model is built, it can be run for different time series.

(ii) Despite the data used in this study being enough for SARIMA and other related models, SARIMA and other related models cannot be used when the data is limited. In that case, the $\operatorname{SGM}(1,1)$ is the key forecasting tool. (iii) This study shows a novel seasonal forecasting model which can be used even if data is limited.

Because of the obtained forecasting performance of SGM $(1,1)$ is satisfactory successful according to the MAPE and $\mathrm{C}$ measures, the forecasting values can be used with complacency. In this section, the requirements of each electrical energy production sources were investigated to meet the electricity demand. The report published by TEIASS in 2013 (TEIASS, 2013) gives the total capacity of the each electrical energy production source. These capacities present the size of installed and under construction capacities which will be available foreseen date. The report gives the annual percentage of the production sources until 2017. In the resource planning process, it is assumed that the values belong to 2018, 2019, and 2020 are the same as 2017. Table 4 presents the share of each source which is used for electricity production.

By using the annual percentage of the production sources and demand forecasting values, maximum requirements of the sources until 2020 are determined as in Table 5. 
Table 4: Share of electricity production sources (\%)

\begin{tabular}{lcccccc}
\hline & 2015 & 2016 & 2017 & 2018 & 2019 & 2020 \\
\hline Brown coal & 12.4 & 12.5 & 12.3 & 12.3 & 12.3 & 12.3 \\
\hline Hard coal & 1.4 & 1.3 & 1.3 & 1.3 & 1.3 & 1.3 \\
\hline Imported coal & 6.9 & 6.7 & 8.2 & 8.2 & 8.2 & 8.2 \\
\hline Natural gas & 35.1 & 34.5 & 34.0 & 34.0 & 34.0 & 34.0 \\
\hline Geothermal & 0.4 & 0.4 & 0.4 & 0.4 & 0.4 & 0.4 \\
\hline Fuel oil & 2.1 & 2.0 & 2.0 & 2.0 & 2.0 & 2.0 \\
\hline Biogas & 0.3 & 0.3 & 0.3 & 0.3 & 0.3 & 0.3 \\
\hline Hydraulics & 37.2 & 37.9 & 37.2 & 37.2 & 37.2 & 37.2 \\
\hline Wind & 3.9 & 4.0 & 3.9 & 3.9 & 3.9 & 3.9 \\
\hline Other & 0.3 & 0.3 & 0.3 & 0.3 & 0.3 & 0.3 \\
\hline
\end{tabular}

Table 5: Maximum monthly requirement of each source until 2020 (106 kWh)

\begin{tabular}{lcccccc}
\hline & 2015 & 2016 & 2017 & 2018 & 2019 & 2020 \\
\hline Brown coal & 3139.308 & 3235.904 & 3420.292 & 3648.948 & 3981.888 & 4212.280 \\
\hline Hard coal & 354.438 & 365.344 & 386.162 & 411.978 & 449.568 & 475.580 \\
\hline Imported coal & 1746.873 & 1800.624 & 1903.227 & 2030.463 & 2215.728 & 2343.930 \\
\hline Natural gas & 8886.267 & 9159.696 & 9681.633 & 10328.877 & 11271.312 & 11923.470 \\
\hline Geothermal & 101.268 & 104.384 & 110.332 & 117.708 & 128.448 & 135.880 \\
\hline Fuel oil & 531.657 & 548.016 & 579.243 & 617.967 & 674.352 & 713.370 \\
\hline Biogas & 75.951 & 78.288 & 82.749 & 88.281 & 96.336 & 101.910 \\
\hline Hydraulics & 9417.924 & 9707.712 & 10260.876 & 10946.844 & 11945.664 & 12636.840 \\
\hline Wind & 987.363 & 1017.744 & 1075.737 & 1147.653 & 1252.368 & 1324.830 \\
\hline Other & 75.951 & 78.288 & 82.749 & 88.281 & 96.336 & 101.910 \\
\hline
\end{tabular}

\section{Conclusions and policy implications}

In this study, a new method based on GM $(1,1)$ and referred to as SGM $(1,1)$ has been proposed to forecast the seasonal time series. First, it has been used to analyze the prediction of the monthly electricity demand of Turkey by using the modelling and the test data. The analysis results showed the success of the method. Subsequently it has been used to forecast the monthly electricity demand until 2020, and the forecasting values have been used to determine the maximum requirements of electricity production sources. The forecasting values indicated that the maximum requirements of the sources appeared in August for every year. On the other hand, the forecasting results show that the maximum electricity requirements would achieve the $33970 \times 10^{6} \mathrm{kWh}$ in 2020.

The obtained results are important for government decision makers, investors and related institutions. The annual demand shows the total usage although it does not represent the maximum usage at any time in the year. Hence, prediction of monthly demand may help governments in:

(i) Determination of maximum capacity of investments

(ii) Planning the future plant investments

(iii) Making arrangement of maintenance operations (iv) Managing the sustainable electricity supply

(v) Managing import and export policies.

Future studies may focus on daily forecasting.

\section{References}

Akay, D., and Atak, M. 2007. Grey prediction with rolling mechanism for electricity demand forecasting of Turkey. Energy 32:1670-1675.

Al-Shobaki, S., and Mohsen, M., 2008. Modelling and forecasting of electrical power demands for capacity planning. Energy Conversion and Management 49:3367-3375.

Azadeh, A., Ghaderi, S.F., and Sohrabkhani, S. 2008. A simulated-based neural network algorithm for forecasting electrical energy consumption in Iran. Energy Policy 36(7):2637-2644.

Bianco, V., Manca, O., and Nardini, S. 2013. Linear Regression Models to Forecast Electricity Consumption in Italy. Energy Sources, Part B: Economics, Planning, and Policy 8:86-93.

Bildirici M. E., Bakirtas T., and Kayikci F. 2012, Economic growth and electricity consumption: Auto regressive distributed lag analysis, Journal of Energy in Southern Africa 23(4): 29-45

Boran, K. 2014. The Box Jenkins Approach to Forecast Net Electricity Consumption in Turkey. Energy 
Sources, Part A: Recovery, Utilization, and Environmental Effects 36:515-524.

Box G. E. P., Jenkins G. M., Reinsel G. C., Time Series Analysis: Forecasting and Control, 4th Edition, Wiley, 2008

Chang T. S, Ku C. Y, Fu H. P. (2013. Grey theory analysis of online population and online game industry revenue in Taiwan. Technological Forecasting \& Social Change 80: 175-185

Cunkas, M., and Altun, A.A. 2010. Long Term Electricity Demand Forecasting in Turkey Using Artificial Neural Networks. Energy Sources, Part B: Economics, Planning, and Policy 5:279-289.

Cunkas, M., and Taskiran, U. 2011. Turkey's Electricity Consumption Forecasting Using Genetic

Programming. Energy Sources, Part B: Economics, Planning, and Policy 6:406-416.

Chang, P.C., Fan, C.Y., and Lin, J.J. 2011. Monthly electricity demand forecasting based on a weighted evolving fuzzy neural network approach. International Journal of Electrical Power Energy Systems 33:17-27.

Chena, Z., and Wang. X. 2012. Applying the Grey Forecasting Model to the Energy Supply Management Engineering. Systems Engineering Procedia 5:179-184.

Chiang, J.Y., and Chen, C.K. 2008. Application of grey prediction to inverse nonlinear heat conduction problem. International Journal of Heat and Mass Transfer 51:576-585.

De Felice, M. Alessandri, A., and Catalano, F. 2015. Seasonal climate forecasts for medium-term electricity demand forecasting. Applied Energy 137:435-444.

Deng, J.L. 1982. Control preoblems of grey systems. Systems \& Control Letters 1:288-294.

Demirel, O., Kakilli, A, and Tektas, M. 2010. Anfis ve arma modelleri ile elektrik enerjisi yük tahmini. Gazi Üniversitesi Mühendislik-Mimarlık Fakültesi Dergisi 25(3):601-610.

Dilaver, Z., and Hunt, L.C. 2011. Turkish aggregate electricity demand: An outlook to 2020. Energy 36:6686-6696.

Efendi, R., Ismail, Z., and Deris, M.M. 2014. A new linguistic out-sample approach of fuzzy time series for daily forecasting of Malaysian electricity load demand. Applied Soft Computing Journal 28:422430.

El-Telbany, M., and El-Karmi, F. 2008. Short-term forecasting of Jordanian electricity demand using particle swarm optimization. Electrical Power and Energy Systems 78(3):425-433.

Electricity Generation Company (EGC). 2013. Sector Report of Electric Generation, Ankara, Turkey. [in Turkish]

González-Romera, E., Jaramillo-Morán, M.A., and Carmona-Fernández, D. 2008. Monthly electric energy demand forecasting with neural networks and Fourier series. Energy Conversion and Management 49:3135-3142.

Hamzacebi, C. 2007. Forecasting of Turkey's net electricity energy consumption on sectoral bases. Energy Policy 35:2009-2016.
Hamzaçebi, C., and Es H.A. 2014. Forecasting the annual electricity consumption of Turkey using an optimized grey model. Energy 70:165-171.

Hamzacebi, C., and Kutay, F. 2004 Yapay sinir ağları ile Türkiye elektrik enerjisi tüketiminin 2010 yllına kadar tahmini. Gazi Üniversitesi MühendislikMimarlık Fakültesi Dergisi 19(3):227-233. [in Turkish]

Herrerias, M.J. 2013. Seasonal anomalies in electricity intensity across Chinese regions, Applied Energy 112:1548-1557.

Hsu, C.C., and Chen, C.Y. 2012. Applications of improved grey prediction model for power demand forecasting. Energy Conversion and Management 2003 44, 2241-2249.

International Energy Agency (IEA). 2009. Energy Policies of IEA Conutries: Turkey 2009 Review, Paris, France.

Jain, R.K., Smith, K.M., Culligan, P.J., and Taylor, J.E. 2014. Forecasting energy consumption of multi-family residential buildings using support vector regression: Investigating the impact of temporal and spatial monitoring granularity on performance accuracy. Applied Energy 123:168-178.

Ju, F.Y., and Hong, W.C. 2013. Application of seasonal SVR with chaotic gravitational search algorithm in electricity forecasting. Applied Mathematical Modelling 37:9643-9651.

Kaytez, F., Taplamacioglu, M.C., Cam, E., and Hardalac, F. 2015. Forecasting electricity consumption: A comparison of regression analysis, neural networks and least squares support vector machines. Electrical Power and Energy Systems 67:431-438.

Liu, S., and Lin, Y. 2010. Grey Systems: Theory and Application. Berlin: Springer-Verlag.

Lü X., Lu W. 2012. Pre-alarm model of diesel vapour detection and alarm based on grey forecasting. Measurement 45: 656-662

Mao, M., and Chirwa, E.C. 2006. Application of grey model $\operatorname{GM}(1,1)$ to vehicle fatality risk estimation. Technological Forecasting and Social Change 73:588-605.

Ministry of Energy and Natural Resources (MENR). 2013. Annual Report 2013, Ankara, Turkey. [in Turkish]

Meng, M., and Niu, D. 2011. Annual electricity consumption analysis and forecasting of China based on few observations methods. Energy Conversion and Management 52:953-957.

Mohamed, Z., and Bodger, P. 2005. Forecasting electricity consumption in New Zealand using economic and demographic variables. Energy 30:1833-1843.

Pankliba, K., Prakasvudhisarnb, C., and Khummongkolb, D. 2015. Electricity Consumption Forecasting in Thailand Using an Artificial Neural Network and Multiple Linear Regression. Energy Sources Part B: Economics, Planning, and Policy 10:427-434.

Saab, S., Badr, E., and Nasr, G. 2001. Univariate modelling and forecasting of energy consumption: the case of electricity in Lebanon. Energy 26, 1-14.

Sa'ad, S. 2009. Electricity demand for South Korean residential sector. Energy Policy 37(12):5469-5474. 
Sumer, K.K., Goktas, Ö., and Hepsag, A. 2009. The application of seasonal latent variable in forecasting electricity demand as an alternative method. Energy Policy 37: 1317-1322.

Sun, G. 1991. Prediction of vegetable yields by grey model GM(1,1). Journal of Grey System 2:187-197.

Tang, H.W.V., and Yin, M.S. 2012. Forecasting performance of grey prediction for education expenditure and school enrollment. Economics of Education Review 31:452-462.

TEIAŞ Report. 2013. 5-Year Projection of Turkish Electricity Production Capacity, Ankara, Turkey. [in Turkish]

Tseng, F.M., Yu, H.C., and Tzeng, G.H. 2001. Applied hybrid grey model to forecast seasonal time series. Technological Forecasting and Social Change 67:291-302.

Turkish Statistical Institute (TSI). 2013. Statistical Indicators 1923-2013, Ankara, Turkey.

Wang, J., Zhu, W., Zhang, W., and Sun, D. 2009. A trend fixed on firstly and seasonal adjustment model combined with the $\varepsilon$-SVR for short-term forecasting of electricity demand. Energy Policy 37:4901-4909.

Wang, Y.F. 2002. Predicting stock prices using fuzzy grey prediction system. Expert Systems with Applications 22:33-39.

Wang, Y., Wang, J., Zhao, G., and Dong, Y. Application of residual modification approach in seasonal ARIMA for electricity demand forecasting: A case study of China. Energy Policy 48:284-294.

Yao, A.W.L., Chi, S.C., and Chen, J.H. 2003. An improved Grey-based approach for electricity demand forecasting. Electric Power Systems Research 67:217-224.

Zhou, P., Ang, B.W., Poh, K.L. 2006. A trigonometric grey prediction approach to forecasting electricity demand. Energy 31:2839-2847.

Zhu, S., Wang, J., Zhao, W. and Wang, J. 2011. A seasonal hybrid procedure for electricity demand forecasting in China. Applied Energy 88:3807-3815.

Zhu, Z.X., and Cao, H.X. 1998. Prediction of El Nino events using grey model. Journal of Tropical Meteorology 4:359-365. 